Original Article

\title{
EVALUATION OF HAZARDS OF WASTE MATERIALS IN CLINICS AND HOSPITALS : A RESEARCH
}

\author{
Ram Kumar Srivastava ${ }^{1}$, Iqbal Ali ${ }^{2}$, Puneet Wadhawani ${ }^{3}$, \\ Anand Kumar ${ }^{4} \&$ Praveen Awasthi $^{5}$ \\ ${ }^{1,2,3}$ Professors, ${ }^{4}$ Assistant Professor, ${ }^{5}$ Reader, Department of Oral Surgery, Career Postgraduate Institute of Dental \\ Sciences \& Hospital, Ghaila, Sitapur-Hardoi Bypass, Lucknow - 226 020, India. \\ Correspondence : \\ Anand Kumar \\ 272-Eldico-1, Basant Vihar, Lucknow - 226020, India \\ Mobile : +9198381 58061 E-mail : anandkmr901@gmail.com
}

\begin{abstract}
s:
Wastes from the cities and villages cannot be avoided from man's existence. It is essential to safely put these unwanted or discarded material away, in the interest of the community. During human activities a lot of waste matter is produced due to various development project, industrialization and modernization of the community. In this study waste materials were collected from various hospitals and rural and urban residential areas. These wastes were divided into two main categories- Health care waste and domestic waste. The survey indicated $80 \%$ solid waste deals with the domestic and urban waste while only $20 \%$ deals with the health care waste. The health care waste is regarded hazardous and may cause a variety of health risk.
\end{abstract}

Keywords: Urbanization, Health care, pathogens, refuse, segregation

\section{Introduction:}

In any community it is essential to safely put unwanted or discarded material away. Healthy cities and villages cannot thrive with insanitary wastes and indifferent sewage disposal. Waste, nevertheless, cannot be avoided totally from man's existence either, so much so, that each one of us is responsible for about $500 \mathrm{gms}$ of solid waste and 100150 liters of sewage/ sullage every day.

During the human activities, a lot of waste matter is produced with industrial, biological development, modernization and urbanization. There is an increase use of these materials and as a result the productions of variety of waste products are also increased (1).

The waste products are either solid wastes or liquid wastes

\begin{tabular}{|c|}
\hline Access this article online \\
\hline Quick Response Code \\
\hline
\end{tabular}

or excremental filth.

Different types of wastes impinge upon physical, mental and social health of the individual or a community in various ways. Hospital is the places where individual is housed for different periods of time for curative, rehabilitative, preventive or promotive services, as a suspect of disease or when suffering from disease. City hospital, health care institutions and research centers use a wide variety of drugs like cytotoxic drugs, corrosive chemicals and radioactive substance which ultimately become part of hospital waste. In addition, the increased use of disposables in the hospitals has brought in its wake many ills such as inappropriate recycling, unauthorized and illegal reuse and increased quantity of wastes disposal, many timesinfected $(2 \& 3)$.

The exposure to health care waste may result in infections and diseases or injury. The hazardous nature of the medical waste may be because it may contain infectious materials/agents or maybe genotoxic or may be radioactive. It may contain 'sharps' such as blades, syringes and needles etc. The prick of these objects result into the introduction of infected material into the human body (4\&5).

The purpose of the study is to evaluate the waste material collected from the clinics and hospitals and methods to dispose of these materials by various methods. 


\section{Material and Methods:}

The samples (waste materials) were collected from various hospitals in Lucknow district and rural and urban residential areas. The samples were divided into two categories- Hospital waste and Residential (public places under municipal limits of Lucknow and adjacent areas). In the hospital scenario, generation of biochemical waste was done at almost all areas and at all levels. Samplings were collected from various hospitals, nursing homes, clinics, dispensaries and P.H.C.'s for assessment (Table-I). For residential waste, samplings were collected from different areas of Lucknow which includes Indira Nagar, Gomti Nagar, Mahanagar, Aliganj, Nirala Nagar, Kaiserbagh etc. These sampling data of residential areas were taken from Nagar M aha Palika, Lucknow (Table-II)

These waste were again divided into infectious (Health Care) waste and non-infectious (Domestic) waste. Infectious waste (Fig: I) included those waste generated in hospital, which was capable of causing infectious diseases or disability. The infectious waste was also generated in clinical areas. These were taken from:

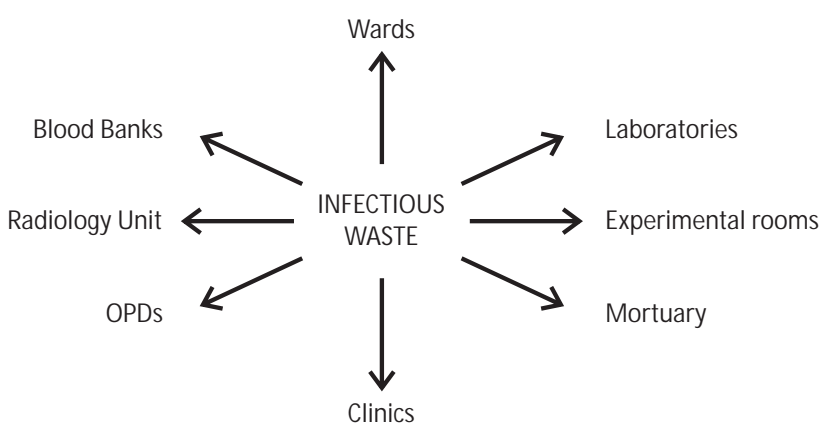

FIG I: Collection of Infectious waste

Non-infectious waste(Fig-II) were included those waste generated from domestic places (urban municipal waste) which were not infectious and does not cause any hazards. These wastes were taken from different sources as under:

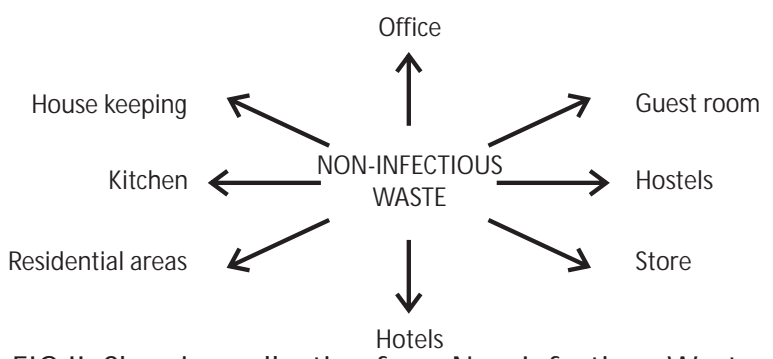

FIG II: Showing collection from Non-Infectious Waste
In our study, the comparison of waste between domestic (Non-infectious) waste and health care (Infectious) waste showed that out of total waste generated in the city $80 \%$ were domestic waste and $20 \%$ were health care waste (Table-III). The health care waste was of small amount as compared to domestic waste. In hospitals, the amount of waste generated per bed varies with the type of hospital, however, on an average 1-5 kg of waste per bed was generated. Estimates of hospital waste were made from number of beds in the city and average amount of waste created per bed. There had been a wide range, depending upon the waste generation and the method of estimation. In Lucknow city, normally 1-5 kg/bed/day of waste was generated. From clinics the solid waste generated was $1 \mathrm{~kg}$ to $1 / 2 \mathrm{~kg}$ per clinic per day. The waste collected from dispensaries and PHCs were $2 \mathrm{~kg}$ to $1 / 2 \mathrm{~kg}$ per dispensary per day. Therefore the average of solid waste generated from health care was 4.5 to $1 / 2 \mathrm{~kg}$ per bed per day (Table-IV).

Waste collected from the residential areas of Nagar M aha Palika was mainly of two types- Solid waste disposal and waste water disposal. The solid waste contributed the maximum percentage of waste (about $80 \%$ of the total waste while the water waste disposal was $15 \%$. The other waste (5\%) included spare parts of vehicles and polythene which could be reusable for various purposes (Table V).

The waste generated from the health care was of different categories. These categories include the infectious and other wastes. The other wastes are pathological waste, sharps, pharmaceutical waste, genotoxic waste, chemical waste, wastes from radioactive heavy metals and pressurized containers. The infectious waste contributed the main waste from the hospitals and nursing homes (45 to $55 \%$ ). The next was the chemical and pharmacological waste (15 to $20 \%$ ). The sharp waste such as blades, knife, and scissors contributed to 10 to $15 \%$. Radioactive waste from $X$-ray matching, radionuclide's associated to about 10 to $15 \%$ (Table VI and Table VII).

\section{Discussion :}

Disposal of wastes is largely the domain of sanitarians and public health engineers. Health professionals need to have 
a basic knowledge of the subject since improper disposal of wastes constitute a health hazard. The solid wastes include garbage (food wastes), rubbish (paper, plastic, wood, metal, glass etc.), demolition product (bricks, masonry and pipes), sewage treatment residues (sludge and solids from the course screening of domestic sewage), dead animals, manure and other discarded materials (6). In cities it is called 'refuse', in country side it is called litter and in general it is called solid waste. The sources of refuse are street refuse (collected by street cleaning services), market refuse (collected from market such as purified vegetables and animal matter), stable litter (collected from stables containing animal droppings and left over animal feeds), industrial refuse (comprises wastes such as calcium carbonate and explosive materials), domestic refuse (such as ash, rubbish and garbage) (7). This indicates that municipal waste is of much more in amount in comparison to hospital waste. The survey conducted indicates that refuse collected from cities amounts about $80 \%$ while the waste collected from hospital was $20 \%$ of the total waste in the cities. Both of these types of wastes are causing a health hazard to the community which ranges from transport of pathogens to man through flies and dust to possibility of water, soil and air pollution. The hospital waste is causing more health problem because of the much percentage of $(45 \%)$ of the infected materials. The other such as sharps chemicals and radioactive materials are also having health hazards to the community.

The waste materials generated by the hospitals may be termed as 'hospital waste', 'medical waste' and 'regulated medical waste' because of variety of wastes generated in the hospital. The term 'medical waste' is used to describe any waste which is generated in the diagnosis, treatment or immunization of human beings or animals. Biomedical waste is used for any solid, fluid or liquid waste including its container and any intermediate product generated during research activities or in the production or testing of biological and animal waste from slaughter houses. Clinical waste is any waste coming out of medical care patient in hospitals or other health care establishments. Pathological waste is the waste removed during surgery/autopsy or other medical procedures including human tissues, organs, body parts, body fluids etc. Infectious waste is that biomedical waste which may transmit viral, bacterial or parasite diseases, if, concentration and virulence of pathogenic organisms is sufficiently high (8). The most appropriate way of identifying the catego ries of health care waste is by sorting the waste into color-coded plastic bags/containers yellow, red, blue, black. The recommended segregation and color coding should be as per central pollution control board regulations. The key to minimization and effective management of health care waste is segregation (separation) and identification of the waste, appropriate handling, treatment and disposal of waste by type, reduce costs and do much to protect public health. Segregation should always be the responsibility of the waste producer, should take place as close as possible to when the waste is generated and should be so maintained in storage areas and during transport. This is important to separate the infected from non-infected waste. In infected waste again segregation should be done for biochemical, pathological, radioactive, sharps waste materials (1\&3).

Thus the survey done in Lucknow City revealed that the quantity of solid waste generated in hospitals and nursing homes generally ranges from $1 / 2 \mathrm{~kg}$ to $4 \frac{1 / 2}{\mathrm{kgs}}$ per bed. The total quantity of hospital waste generated in Lucknow is about 30 tones per day. Out of this nearly 45 to $50 \%$ is infectious; segregation of infectious waste from noninfectious wastes is done only in about $20 \%$ of hospitals. This the survey indicates $80 \%$ solid waste, deals with the normal domestic and urban waste management system while only $20 \%$ dealt with in health care waste. Out of this $16 \%$ are pathological and infectious waste, $1 \%$ sharp waste, $3 \%$ chemical and pharmacological waste, less than $1 \%$ special waste, such as radioactive or cytotoxic waste, pressurized contains or broken thermometers and used batteries. These surveys are also coinciding with the survey conducted in the Bangalore city for the waste management system. 


\section{Conclusion :}

It is concluded from the study that between 75 to 90 percent of the waste produced in the cities is non-risk or 'general' health care waste, comparable to domestic waste. It comes mostly from administrative and house keeping

\section{References:}

1. Park K, (2002) Park's Textbook of preventive and social medicine, $17^{\text {th }}$ ed., Jabalpur, M/s Banarsidas Bhanot,

2. Pruss A, Cirouit E and Rushbrook P, (1999) Safe management of waste from health care activities. WHO,

3. Mahajan BK, Gupta MC,(2003) Textbook of preventive and social medicine, Jaypee Brothers M edical Publishers Pvt. Ltd., New Delhi, $3^{\text {rd }}$ ed.,

4. Madhusudan Krishna, (2006) Principles and practice of public health dentistry, Ist ed., 228-240.

5. Dunning, (2005) Principles of dental public health, 13, 43, 166, 170-76 and 505.

6. Soben Peter, (1998) Essential of preventive and community dentistry, $1^{\text {st }}$ ed., 7-25.

7. Hiremath SS,(2007) Textbook of preventive and community dentistry, $1^{\text {st }}$ ed,

8. Antony W. Jong, (2006) Community dental health, $3^{\text {rd }}$ ed., 3-7. functions of the health care establishment and may also include waste generated during maintenance of health care premises. The remaining 10-25 percent health care waste is regarded hazardous and may create a variety of health risk. 